\title{
Cobalt Fischer-Tropsch Catalyst Regeneration: The Crucial Role of the Kirkendall Effect for Cobalt Redispersion
}

\author{
C. J. Weststrate • M. M. Hauman • D. J. Moodley • \\ A. M. Saib · E. van Steen $\cdot$ J. W. Niemantsverdriet
}

Published online: 2 August 2011

(c) The Author(s) 2011. This article is published with open access at Springerlink.com

\begin{abstract}
Redispersion of cobalt is a key process during Fischer-Tropsch catalyst regeneration. Using model catalysts we show that redispersion is a two step process. Oxidation of supported metallic cobalt nanoparticles produces hollow oxide particles by the Kirkendall effect; reduction leads to break-up of these hollow oxide shells, forming multiple metallic particles. This mechanism is to a large extent independent of the support.
\end{abstract}

Keywords Catalyst regeneration - Fischer-Tropsch synthesis $\cdot$ Kirkendall effect

\section{Introduction}

Supported cobalt is the catalyst of choice for the FischerTropsch synthesis (FTS) step in the gas-to-liquid process (GTL) due to its high activity and selectivity to linear paraffins. Due to the cost of both cobalt and noble metals, which are often used as promoters, extended catalyst life, is required to make the process economically feasible. Apart from the synthesis of a relatively stable fresh catalyst

C. J. Weststrate $(\bowtie) \cdot$ J. W. Niemantsverdriet

Schuit Institute of Catalysis, Eindhoven University

of Technology, P.O. Box 513, 5600 MB Eindhoven,

The Netherlands

e-mail: c.j.weststrate@tue.nl

M. M. Hauman · D. J. Moodley · A. M. Saib

Sasol Technology Pty (Ltd.), P.O. Box 1, Sasolburg 1947,

South Africa

E. van Steen

Centre for Catalysis Research, Department of Chemical Engineering, University of Cape Town, Private Bag X3, Rondebosch, Cape Town 7701, South Africa regeneration can be used to extend the lifetime of Co FTS catalysts [1-3]. A fundamental understanding of the deactivation mechanisms at play during FTS is key to designing an efficient regeneration process. Most of the research on cobalt catalyst deactivation in the last 15 years has focused on oxidation as a deactivation mechanism [1]. Our previous work however, showed that oxidation is not a deactivation mechanism during FTS for supported Co catalysts with crystallite size in excess of $2 \mathrm{~nm}[1,4-6]$. On the contrary, the FT environment was found to be strongly reducing [4]. Following a comprehensive study into the deactivation of a cobalt catalyst under realistic FTS conditions the following intrinsic deactivation mechanisms were identified (1) sintering of Co active phase [1, 7] (2) carbon deposition [1,8] and (3) possibly surface reconstruction $[1,9,10]$. Having identified these mechanisms a three step regeneration process, i.e. (1) dewaxing (2) oxidation and (3) reduction, was tailored to reverse the sintering, carbon deposition and surface reconstruction that takes place during FTS. The oxidation step was found to be crucial in burning off the deleterious carbon and redispersing the cobalt [1]. To date there is little fundamental understanding on the mechanism of redispersion of the Co during regeneration. This understanding is crucial in the design and improvement of catalyst regeneration. The following paper aims to elucidate the mechanism of redispersion during regeneration for an alumina supported catalyst. Due to the complexity of the real catalyst, model systems were used to fundamentally understand the mechanism of redispersion during regeneration.

For redispersion of the cobalt phase cobalt needs to be mobile, with a net movement away from the location of the original particle. We have used flat model catalysts (silica and alumina) that are compatible with TEM imaging, as well as a non-porous $\alpha$-alumina-supported model catalyst. 
The flat model system gives excellent contrast in the TEM, and allows us to locate practically all the cobalt [11]. Furthermore, the sample can be subjected to further treatments after imaging, after which the same sample area can be imaged again. This is an excellent tool to study morphology changes on the level of individual particles and study cobalt transport phenomena over the support in detail. By varying the support its influence can be studied as well. The use of $\alpha$-alumina as a support is closer to a real catalyst support, but the absence of pore structure allows for easier interpretation of the TEM images. A further advantage of this model catalyst is that it can be characterized by standard catalyst characterization techniques, such as X-ray diffraction (XRD).

\section{Experimental}

\subsection{Flat Model Systems}

Details about the flat model support can be found elsewhere [11]. Briefly, the sample consists of a silicon wafer covered with a $15 \mathrm{~nm}$ thick silicon nitride membrane terminated with a $3 \mathrm{~nm}$ thick silicon oxide layer. In the center of the sample a small part of the underlying silicon wafer is etched away, leaving only the membrane, thin enough to facilitate TEM imaging. A flat alumina support was created by sputter-deposition of $\gamma$-alumina on top of the silica sample. SEM, AFM and XPS analysis showed a continuous $\sim 5 \mathrm{~nm}$ thick alumina layer with a roughness of $\sim 1 \mathrm{~nm}$, similar to that of the silica substrate. The Auger parameter of the alumina $(1461.4 \mathrm{eV})$ falls between that of amorphous alumina and $\gamma$-alumina [12-14]. When the membrane breaks it tends to curl up, thus providing a side view of the support surface, which gives information about the $z$-coordinate of the sample.

Cobalt was deposited by spincoating of a cobalt nitrate solution. A polymer (PMVE) was added to the spincoating solution, which serves mainly to increase the viscosity of the spincoating solution. The spincoating solution was prepared using $20 \mathrm{~g}$ of a $25 \%$ PMVE solution in water, to which $3 \mathrm{~g}$ of isopropanol was added. $0.5 \mathrm{~mL}$ of a $65 \mathrm{mM}$ cobalt nitrate solution was added to $5 \mathrm{~mL}$ of the PMVE/ water/isopropanol mixture, resulting in a cobalt concentration of $5.9 \mathrm{mM}$. For the alumina-support samples a small amount of $\mathrm{Pt}$ was added in the form of platinum ammonium nitrate, to serve as a reduction promoter. The $\mathrm{Pt}$ concentration in the spincoating solution was $4.5 \mu \mathrm{M}$, that is, a Co:Pt ratio of 1,320:1.

After spincoating the samples were calcined at $350{ }^{\circ} \mathrm{C}$ for $3 \mathrm{~h}\left(5^{\circ} \mathrm{C} / \mathrm{min}, 20 \% \mathrm{O}_{2}\right.$ in Ar), during which the cobalt nitrate was converted into cobalt oxide $\left(\mathrm{Co}_{3} \mathrm{O}_{4}\right)$ and the polymer was burnt off (confirmed by XPS). During further oxidation steps the same temperature program and gas composition were used. Reduction was performed at $425{ }^{\circ} \mathrm{C}\left(2{ }^{\circ} \mathrm{C} / \mathrm{min}, 4 \mathrm{~h}\right)$, in pure $\mathrm{H}_{2}$. After cooling down to room temperature in hydrogen the samples were passivated by controlled exposure to air.

XPS was measured with a Kratos AXIS Ultra spectrometer, equipped with a monochromatic $\mathrm{Al} \mathrm{K} \alpha \mathrm{X}$-ray source, a twin anode source ( $\mathrm{Al}$ and $\mathrm{Mg}$ ) and a delay-line detector (DLD). Spectra were obtained using the aluminum anode ( $\mathrm{Al} \mathrm{K} \alpha=1486.6 \mathrm{eV}$ ) operating at $150 \mathrm{~W}$. Binding energies were calibrated to $\mathrm{Si} 2 \mathrm{p}$ peak of amorphous silica at $103.3 \mathrm{eV}$. The Auger parameter of the alumina layer was determined using the $\mathrm{Al}$ anode of a twin source, where the bremsstrahlung is responsible for the $\mathrm{Al} \mathrm{KL}_{23} \mathrm{~L}_{23}$ Auger peaks. The TEM studies were carried out on a Tecnai 20 (FEI Co.) operated at $200 \mathrm{kV}$. For both the XPS and TEM measurements the samples were exposed to air before measurements.

\section{$2.2 \alpha$-Alumina-Supported Model Systems}

Ceralox APA-0.5 ( $\alpha$-alumina, surface area $8 \mathrm{~m}^{2} / \mathrm{g}$, Sasol Germany GMBH) was impregnated with an aqueous cobalt nitrate solution with the appropriate concentration to produce a $10 \mathrm{wt} \%$ cobalt on alumina model catalyst. After vacuum drying at $75-85^{\circ} \mathrm{C}$ the sample was calcined in air at $250{ }^{\circ} \mathrm{C}\left(1{ }^{\circ} \mathrm{C} / \mathrm{min}, 6 \mathrm{~h}\right)$ in a fluidized bed. Reduction was performed in pure hydrogen at $425{ }^{\circ} \mathrm{C}\left(1{ }^{\circ} \mathrm{C} / \mathrm{min}, 10 \mathrm{~h}\right)$, followed by passivation in dry ice in an inert atmosphere. Controlled exposure to air produces a $3 \mathrm{~nm} \mathrm{CoO}$ passivation layer which protects the particles from further oxidation. XRD measurements were performed using a Philips $X$ 'Pert Pro multi-purpose diffractometer equipped with a $\mathrm{Co} \mathrm{K} \alpha$ source. Average $\mathrm{Co}_{3} \mathrm{O}_{4}$ particle sizes were obtained by a full pattern refinement procedure. TEM measurements were performed on a JEOL 2010 microscope equipped with a $\mathrm{LaB}_{6}$ filament and operated at $200 \mathrm{kV}$.

\section{Results}

\section{$3.1 \mathrm{Co} / \mathrm{SiO}_{2}$}

After spincoating, calcination and reduction a typical silicasupported flat model sample contains metallic cobalt particles, covered with a $\sim 3 \mathrm{~nm}$ thick $\mathrm{CoO}$ passivation layer. This was confirmed by XPS analysis, where a mixture of metallic $\mathrm{Co}$ and $\mathrm{CoO}$ was detected. Figure 1(a) shows a TEM image of a reduced sample. A variety of particle sizes is observed, with diameters between $30 \mathrm{~nm}$ and $3 \mathrm{~nm}$.

Oxidation of the (passivated) metallic cobalt particles leads to drastic morphology changes (Fig. 1b). The 
Fig. 1 a, b Bright field TEM images of a cobalt-covered flat model silica support, showing the same sample area before and after reoxidation. In panel (c) outline and position of the original metallic particles is indicated, on top of the reoxidized picture to facilitate detailed comparison. A broken membrane curls up and in this way images with a tilted membrane can be obtained, including a side view of the membrane (d). These images confirm that the hollow particles are closed on the top. e Electron diffraction shows diffuse diffraction rings typical of polycrystalline $\mathrm{Co}_{3} \mathrm{O}_{4}$

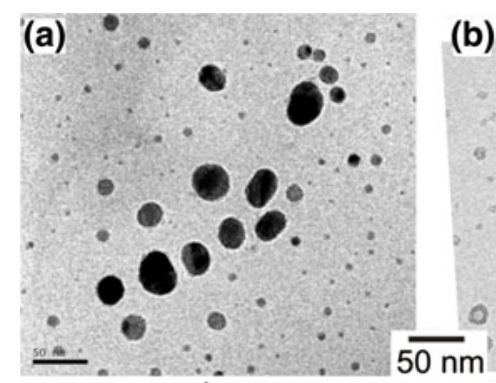

red. (b)

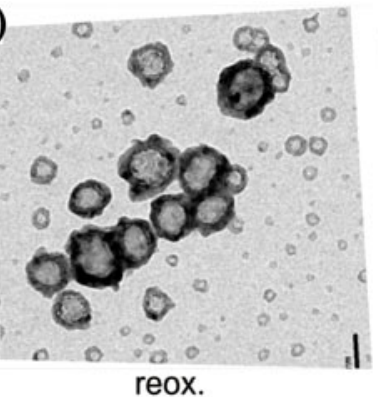

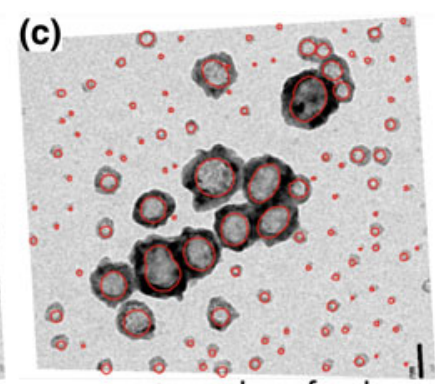

reox.+ overlay of red.
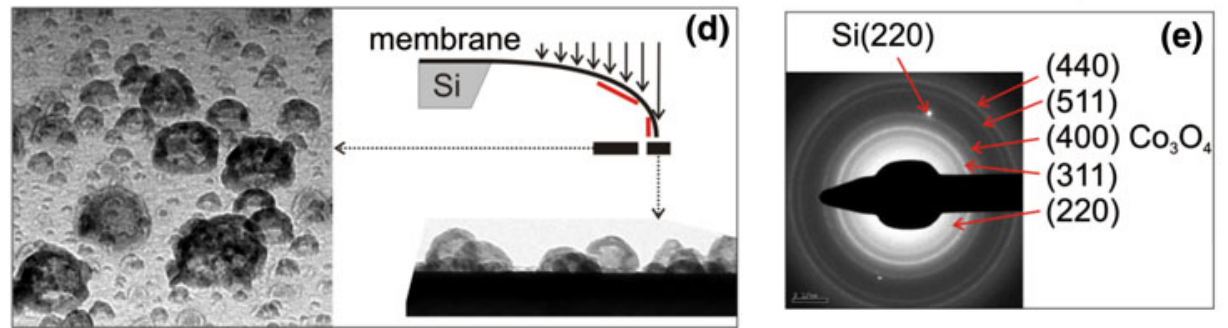

formation of hollow oxide particles is observed, with a significantly larger diameter than the original metal particle. Detailed comparison between the particles before and after oxidation by overlaying the outline of the metallic particles with the same particles in the oxidized form (Fig. 1c) shows (1) that the particles have not moved over the support, i.e. the hollow particles are centered on the location of the original metal particle and have not moved over the support. (2) The inner diameter of the hollow oxide particle is equal to the size of the original metal particle. (3) The same process occurs for different particle sizes.

Images in which the membrane is tilted (up to $90^{\circ}$, creating a side view) with respect to the electron beam provide information about the $z$-direction of the sample. These images (Fig. 2d) clearly show that the hollow particles are closed on the top, so they are most accurately described as hollow (hemi-) spheres instead of doughnuts. Electron diffraction and XPS show that the hollow particles consist of $\mathrm{Co}_{3} \mathrm{O}_{4}$. The Co $2 \mathrm{p}$ spectrum is identical to a $\mathrm{Co}_{3} \mathrm{O}_{4}$ reference. Silicate formation would lead to an increase of the $\mathrm{Co}^{2+}$-related peaks with respect to the reference. Thus, we found no indication for silicate formation. The electron diffraction image (Fig. 2e) shows diffuse rings instead of more discreet spots, indicating that the oxide shell is highly polycrystalline, in line with the findings of other authors $[16,17]$.

\subsubsection{Re-reduction}

Figure 2 summarizes the results obtained after reduction of the hollow oxide shells. It shows the same sample area during the different stages of oxidation-reduction. From these images it is clear that redispersion of the cobalt particles has occurred after oxidation-reduction: the hollow oxide particles formed upon oxidation break up into several metallic cobalt particles during reduction. These particles form a ring-like structure on the support, located at the position of the original oxide shell. Thus, it is obvious that regeneration has led to an increase in the surface area, as a single large metal particle is converted into several smaller metal particles. All the metallic cobalt particles are found at the location where oxide was present before reduction, showing that cobalt mobility over the support (sintering) was low during reduction at $425^{\circ} \mathrm{C}$.

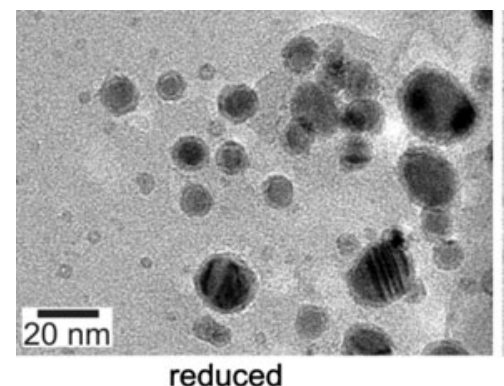

reduced

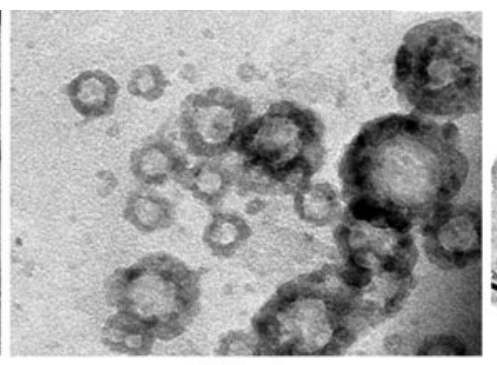

reoxidized

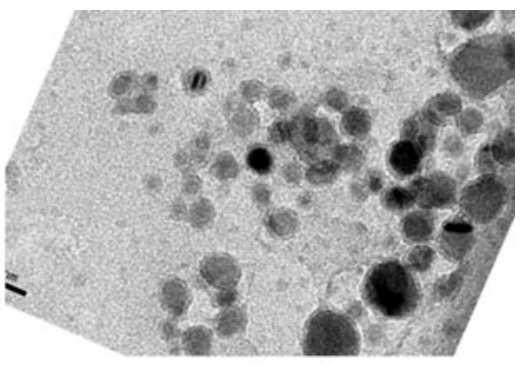

re-reduced

Fig. 2 Bright field TEM images of the same sample area during the different steps of the oxidation-reduction treatment. It can be seen that reduction of the hollow particles leads to redispersion of the cobalt phase 


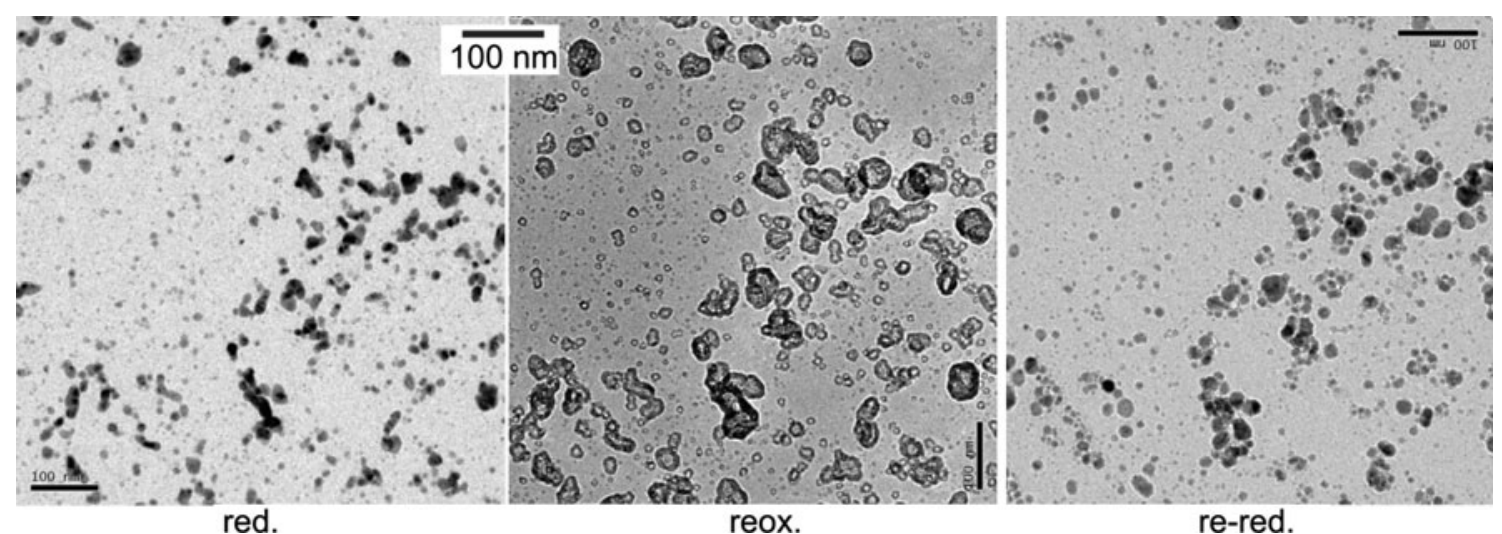

Fig. 3 Bright field TEM images of a flat cobalt-on-alumina flat model catalyst, showing the reduced, reoxidized and re-reduced form of the same sample area. Hollow oxide particle are formed during oxidation, and they break up during reduction, similar to the silica system

\section{$3.2 \mathrm{Co} / \mathrm{Al}_{2} \mathrm{O}_{3}$}

The role of the support was studied by using a model alumina support instead of silica. The results of this study are summarized in Fig. 3. Alumina is a more reactive support, which in general makes it more difficult to reduce alumina-supported cobalt. From our samples it is difficult to measure the degree of reduction directly, and the influence of the support is mostly seen indirectly: the metallic particles on alumina look more irregular, and the larger agglomerates appear not fully separated in contrast to the silica samples shown in Fig. 1. We tentatively explain this by incomplete reduction of the alumina-supported cobalt oxide [4]. In this article we will only focus on the effect of the support on the redispersion process. Reoxidation of the alumina-supported sample leads, similar to the silica sample, to the formation of hollow oxide particles, and reduction of the hollow particles shows break-up of the hollow oxide particles. Although the results on flat alumina are certainly not conclusive it is clear that the nature of the support does not fundamentally change the redispersion mechanism found on a silica support.

\subsection{1 $\alpha$-Alumina-Supported Model Systems}

A study of non-porous $\alpha$-alumina-supported cobalt revealed a similar redispersion mechanism. In this article we only show a small part of the work, merely to illustrate that the flat model work can be extended to more realistic supported systems. A full report on this work will be published elsewhere. Figure 4 shows TEM images of an $\alpha$ alumina-supported cobalt catalyst during different stages in a reduction-oxidation-reduction procedure. The sample in the reoxidized phase (center image) shows the formation of hollow oxide particles. When comparing the reduced state before and after oxidation it is clear that the larger cobalt particles have completely disappeared, and instead a large number of small cobalt crystallites are seen. XRD was performed in the calcined and reoxidized state. The average $\mathrm{Co}_{3} \mathrm{O}_{4}$ particle diameter in the fresh sample before the

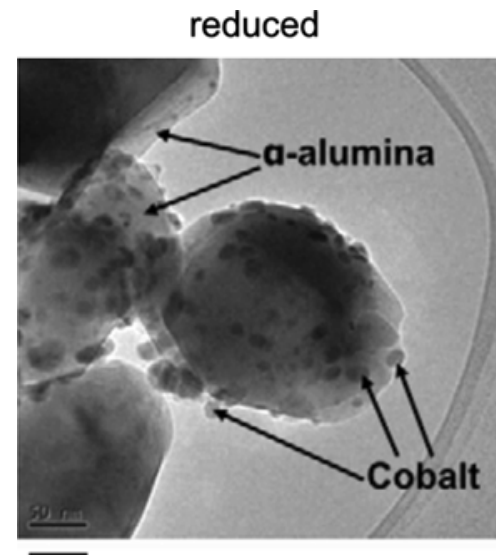

$\overline{50 \mathrm{~nm}}$

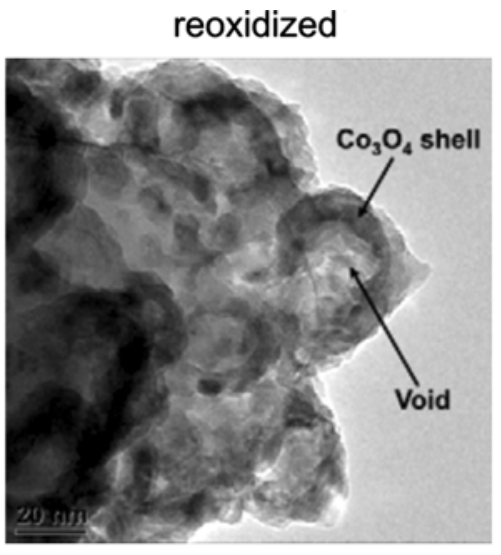

$\overline{20 \mathrm{~nm}}$

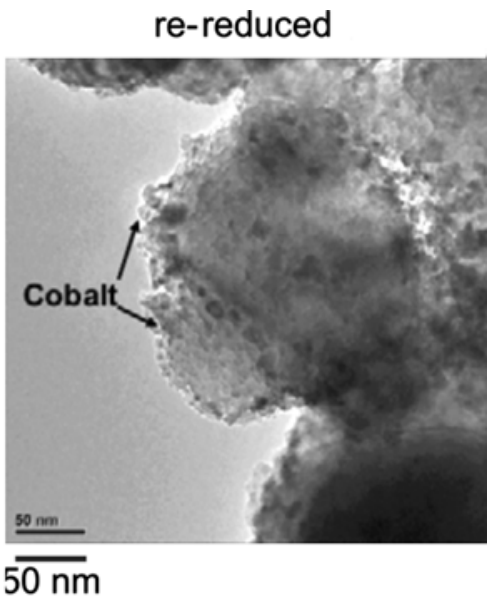

$\overline{50 \mathrm{~nm}}$

Fig. 4 Bright field TEM images of a $\alpha$-alumina-supported cobalt model catalyst, showing the formation of hollow oxide spheres in the reoxidized stage and higher metallic cobalt dispersion in the re-reduced state 
first reduction step is $30 \mathrm{~nm}$, while the average particle size in the reoxidized sample is $9 \mathrm{~nm}$. This smaller XRD particle size in the reoxidized state can be rationalized by special morphology in the reoxidized state: the cobalt oxide is present in the form of hollow polycrystalline particles, and XRD only detects the average size of the individual crystallites that make up the hollow oxide shell $[15,16]$. We did not find indications for aluminate formation in either of the alumina model catalysts.

\section{Discussion}

A spent alumina-supported FT catalyst can be regenerated using a procedure that involves solvent wash to remove excess wax, oxidation to remove residual carbon and to redisperse the cobalt, followed by a reactivation using hydrogen [1]. Our model systems with different levels of complexity capture the essential elements of a spent FT catalyst after dewaxing: the samples have a high degree of reduction, similar to what is found for spent samples [4]. Our samples contain both large and small particles, thus mimicking a sintered catalyst. This makes our findings on the model systems highly relevant to understand the processes that occur during regeneration of a real cobalt FT catalyst.

Cobalt mobility over the support is a crucial parameter in cobalt redispersion. During FT synthesis the initially well-dispersed metallic system tends to sinter, an inevitable process driven by thermodynamics. The gas atmosphere can have a strong influence on the kinetics of sintering, i.e. on the cobalt mobility, as shown, for example, in Ref. [17]. Reversal of sintering, redispersion requires a mechanism that favors spreading of the cobalt phase. On the flat model samples, where virtually al the cobalt can be seen, the mobility of cobalt over the support was found to be low, both during oxidation and during reduction. The only significant cobalt mobility over the support that was seen in our experiments is limited to the formation of hollow oxide shells during oxidation of the metal particle. It is also the kind of mobility needed for redispersion: cobalt is transported away from its original location.

The formation of hollow oxide particles upon oxidation has been reported previously, on several metals including $\mathrm{Co}, \mathrm{Ni}, \mathrm{Fe}$ and $\mathrm{Cu}[15,16,18-20]$, and the mechanism responsible for this is the Kirkendall effect, where diffusivity differences of the reactants in solid state reactions results in void formation [21-23]. In the case of oxidation of metallic nanoparticles the outward diffusion of the metal (cations) through the growing oxide layer is much faster than the inward diffusion of oxygen. Thus, the oxide layer grows on the outside, ultimately creating a hollow oxide particle. In our particular system the size of the inner void is equal to the size of the original metal particle, which implies that the inward diffusion of oxygen is negligible.

During reduction the cobalt mobility has to be low, in order to avoid complete reversal of the cobalt redispersion due to the Kirkendall effect. This is exactly what we observe after reduction: Rather than collapsing back into a single metal particle, the hollow shells break up, forming multiple smaller metallic cobalt particles at the location of the original cobalt oxide shell.

The exact nature of the support does not fundamentally change redispersion via the Kirkendall mechanism. The silica and alumina flat model systems and the more realistic $\alpha$-alumina-supported model system show the same redispersion mechanism. The formation of hollow cobalt oxide particles for montmorillonite-supported Co confirms the view that the Kirkendall effect is a general mechanism that occurs on any type of support. Thus, a similar redispersion mechanism can be expected on a real FT catalyst as well.

\section{Conclusions}

We have used model cobalt catalysts to study the mechanism of cobalt redispersion during an oxidation-reduction treatment. Metallic cobalt oxidizes via formation of hollow oxide particles, with an inner void that has the size of the original metal particle. Thus cobalt is transported away from its original position during oxidation, an important first step for cobalt redispersion. The second step of redispersion occurs during reduction of the hollow particles: they break up into several smaller cobalt particles, located in a ring around the position of the original oxide shell. As the cobalt transport via the Kirkendall mechanism was the only source of cobalt mobility on the support we conclude that this mechanism is a crucial ingredient of catalyst regeneration. This redispersion mechanism is independent to a large extent of the support, and it is therefore believed to responsible for cobalt redispersion during regeneration of a real FT catalyst as well.

Open Access This article is distributed under the terms of the Creative Commons Attribution Noncommercial License which permits any noncommercial use, distribution, and reproduction in any medium, provided the original author(s) and source are credited.

\section{References}

1. Saib AM, Moodley DJ, Ciobîcă IM, Hauman MM, Sigwebela BH, Weststrate CJ, Niemantsverdriet JW, van de Loosdrecht J (2010) Catal Today 154:271

2. Huang R, Agee KL, Arcuri BA, Schubert PF, US 6,812,179B2, US2002/0183403 A1; WO 02/085508 (Syntroleum)

3. Burgt van der MJ, Ansorge J, GB 2,222,531, 1988 (Shell) 
4. Saib AM, Borgna A, van de Loosdrecht J, van Berge PJ, Niemantsverdriet JW (2006) Appl Catal A 312:12

5. Saib AM, Borgna A, van de Loosdrecht J, van Berge PJ, Niemantsverdriet JW (2006) J Phys Chem B 110:8657

6. van de Loosdrecht J, Balzhinimaev B, Dalmon J-A, Niemantsverdriet JW, Tsybulya SV, Saib AM, van Berge PJ, Visagie JL (2007) Catal Today 123:293

7. Overett MJ, Breedt B, Du Plessis E, Erasmus W, van de Loosdrecht J (2008) Prep Pap-Am Chem Soc Div Petr Chem 53:126

8. Moodley DJ, van de Loosdrecht J, Saib AM, Overett MJ, Datye AK, Niemantsverdriet JW (2009) Appl Catal A 354:102

9. Ciobîcă IM, van de Loosdrecht J, van Berge PJ, van Santen RA (2008) Surf Sci 602:17

10. Tsakoumis NE, Rønning M, Borg Ø, Rytter E, Holmen A (2010) Catal Today 154:162

11. Moodley P, Scheijen FJE, Niemantsverdriet JW, Thüne PC (2010) Catal Today 154:142

12. Wagner CD, Passoja DE, Hillery HF, Kinisky TG, Six HA, Jansen WT, Taylor JA (1982) J Vac Sci Technol 21:933
13. Moretti G, Porta P (1993) Surf Interface Anal 20:675

14. Frederick BG, Apai G, Rhodin TN (1991) Surf Sci 244:67

15. Yin Y, Rioux RM, Erdonmez CK, Hughes S, Somorjai GA, Alivisatos AP (2004) Science 304:711

16. Chernavskii PA, Pankina GV, Zaikovskii VI, Peskov NV, Afanasiev P (2008) J Phys Chem C 112:9573

17. Bezemer GL, Remans TJ, van Bavel AP, Dugulan AI (2010) J Am Chem Soc 132:8540

18. Railsback JG, Johnston-Peck AC, Wang J, Tracy JB (2010) ACS Nano 4:1913

19. Cabot A, Puntes VF, Shevchenko E, Yin Y, Balcells L, Marcus MA, Hughes SM, Alivisatos AP (2007) J Am Chem Soc 129:10358

20. Hung L, Tsung CK, Huang W, Yang P (2010) Adv Mater 22:1910

21. Fan HJ, Knez M, Scholz R, Hesse D, Nielsch K, Zacharias M, Gösele U (2007) Nano Lett 7:993

22. Fan HJ, Gösele U, Zacharias M (2007) Small 3:1660

23. Smigelskas AD, Kirkendall EO (1947) Trans AIME 171:130 